\title{
Change in methodology for collection of drinking water intake in What We Eat in America/National Health and Nutrition Examination Survey: implications for analysis
}

\author{
Rhonda S Sebastian*, Cecilia Wilkinson Enns, Joseph D Goldman and Alanna J Moshfegh \\ US Department of Agriculture, Agricultural Research Service, Beltsville Human Nutrition Research Center, \\ Food Surveys Research Group, BARC-West, Building 005, Room 102, Beltsville, MD 20705-2350, USA
}

Submitted 5 July 2011: Accepted 12 January 2012: First published online 20 February 2012

\begin{abstract}
Objective: To provide updated estimates of drinking water intake (total, tap, plain bottled) for groups aged $\geq 1$ year in the USA and to determine whether intakes collected in 2005-2006 using the Automated Multiple-Pass Method for the $24 \mathrm{~h}$ recall differ from intakes collected in 2003-2004 via post-recall food-frequency type questions.

Design: Cross-sectional, observational study.

Setting: What We Eat in America (WWEIA), the dietary intake component of the US National Health and Nutrition Examination Survey (NHANES).

Subjects: Individuals aged $\geq 1$ year in 2003-2004 ( $n$ 8249) and 2005-2006 ( $n$ 8437) with one complete $24 \mathrm{~h}$ recall.

Results: The estimate for the percentage of individuals who reported total drinking water in $2005-2006$ was significantly $(P<0 \cdot 0000)$ smaller $(76 \cdot 9 \%)$ than that for 2003-2004 (87.1\%), attributable to a lower percentage reporting tap water $(54 \cdot 1 \%$ in $2005-2006 v \cdot 67 \cdot 0 \%$ in 2003-2004; $P=0 \cdot 0001)$. Estimates of mean tap water intake differed between the survey cycles for men aged $\geq 71$ years.

Conclusions: Survey variables must be examined before combining or comparing data from multiple WWEIA/NHANES release cycles. For at least some age/gender groups, drinking water intake data from NHANES cycles prior to 2005-2006 should not be considered comparable to more recent data.
\end{abstract}

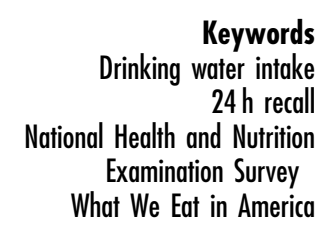

Nationwide survey data permit estimation of water intake both as a nutrient (total water/moisture; see definitions in Table 1) and as a beverage (drinking water). The latter is of interest for a broad range of research. Nationally representative estimates of the intake of drinking water, combined with estimates of moisture intake from food and other beverages, were used in developing the Dietary Reference Intakes for total water for the USA and Canada $^{(1)}$. In the literature, many studies consider drinking water in its role as a vehicle for water-borne nutrients, chemical contaminants and micro-organisms ${ }^{(2,3)}$; others focus on the benefits of consuming water rather than other beverages (e.g. reference ${ }^{(4)}$ ).

The US Department of Agriculture (USDA) and the US Department of Health and Human Services have a long history of collecting intake information on all types of water. The two Departments have partnered in dietary intake data collection since 2002, conducting the survey What We Eat in America (WWEIA) as the dietary intake interview component of the National Health and Nutrition Examination Survey (NHANES). The $24 \mathrm{~h}$ dietary recall method used in WWEIA is the USDA five-step Automated
Multiple-Pass Method (AMPM) ${ }^{(5)}$. The addition of the collection of drinking water intake data to the AMPM recall was initiated in WWEIA 2005-2006. Before 20052006, plain water intake data were collected after the $24 \mathrm{~h}$ recall via food-frequency type questions which asked the respondent to estimate the total amounts of tap and bottled water consumed the previous day. Based upon a comprehensive review of water consumption studies, an international panel concluded that a diary is the preferred method for collection of water intake data, but that if a diary is not feasible then a $24 \mathrm{~h}$ recall method - rather than an FFQ - is the best alternative for obtaining valid, complete water intake reports $^{(3)}$.

Certain research questions require either comparing or combining data from multiple NHANES cycles. For example, trends analysis, by definition, compares variables of interest across time. The NHANES analytic guidelines strongly recommend that researchers who wish to analyse data for specific demographic sub-domains (e.g. by race/ethnicity within age/gender group) combine data from consecutive two-year cycles in order to produce estimates with greater statistical reliability ${ }^{(6)}$. Before performing analyses of these 
Table 1 Glossary of water terms used in the present paper

\begin{tabular}{|c|c|}
\hline Moisture & $\begin{array}{l}\text { Also referred to as 'total water'. The sum of } \\
\text { all water (moisture) from all sources, } \\
\text { including total plain drinking water, other } \\
\text { beverages and food }\end{array}$ \\
\hline $\begin{array}{l}\text { Water, (plain) } \\
\text { bottled }\end{array}$ & $\begin{array}{l}\text { All bottled water except sweetened, } \\
\text { carbonated and/or fortified bottled water. } \\
\text { Includes water from a water cooler }\end{array}$ \\
\hline Water, (plain) tap & $\begin{array}{l}\text { All tap water. Includes filtered tap water } \\
\text { and water from a drinking fountain }\end{array}$ \\
\hline $\begin{array}{l}\text { Water, total (plain) } \\
\text { drinking }\end{array}$ & The sum of all plain tap and bottled water \\
\hline
\end{tabular}

types, however, users are instructed to confirm that data items collected in all survey cycles included in the analysis are comparable in wording and methods. Because of the change in method, a comparison of the 2005-2006 estimates of drinking water intake with earlier estimates is of interest.

Although a few studies have analysed current US intake data collected using this new methodology ${ }^{(7-10)}$, no study to date has reported intakes of total drinking, tap and bottled water for all age and gender groups.

The goals of the present study were twofold: for individuals aged $\geq 1$ year, (i) to provide updated national estimates of total drinking, tap and bottled water collected in 2005-2006 using the AMPM; and (ii) to compare these estimates with estimates based on data collected in 2003-2004 using the old frequency-type questions.

\section{Methods}

\section{Sample}

Water intake estimates presented are based on data from 8437 individuals aged $\geq 1$ year who provided one complete day of dietary recall data in WWEIA/NHANES 2005-2006 ${ }^{(11)}$. Although more current data have become available (WWEIA/NHANES 2007-2008), the comparison of water estimates across survey cycles was carried out using the data sets immediately before and after the methodological change in order to minimize the effect of time on water consumption patterns. Earlier data used for comparisons are from 8249 individuals the same age interviewed in WWEIA/NHANES 2003-2004 ${ }^{(12)}$.

The NHANES samples for both 2003-2004 and 2005-2006 were designed to be representative of the civilian, noninstitutionalized US population, with oversampling of persons aged $12-19$ years and $\geq 60$ years, low-income persons, non-Hispanic blacks, Mexican Americans and pregnant women to improve accuracy of related estimates ${ }^{(13,14)}$. The data and accompanying documentation are available online for both surveys ${ }^{(11,12)}$. Breast-feeding children and pregnant and lactating females were excluded from all analyses.

\section{Water intake data}

In the present study, the term 'total drinking water' refers to the sum of tap water plus plain bottled water (i.e. bottled water without added sweetener or carbonation) that was consumed as a beverage. Water consumed as a component of another beverage or food (such as that contained in bottled drinks, used in brewing coffee or added when reconstituting condensed soup) is excluded.

Before and during WWEIA 2003-2004, intake information on tap and plain bottled water was collected after the $24 \mathrm{~h}$ recall, and information on sweetened water was collected during the $24 \mathrm{~h}$ recall $^{(12,15)}$. In general, tap and plain bottled water questions resembled food-frequency questions in that the respondent was asked to give a single estimate of total consumption for the day (Table 2).

Starting in WWEIA 2005-2006, data on all types of water are collected during the $24 \mathrm{~h}$ recall in the same manner as for all other beverages and foods ${ }^{(5,11,16)}$. Item-specific information (such as type, amount, time and name of eating occasion, etc.) that is obtained about foods and non-water beverages is now also captured for drinking water.

\section{Statistical analyses}

Analyses were carried out using the statistical software packages SAS release $9 \cdot 1 \cdot 3$ (SAS Institute, Cary, NC, USA) and SUDAAN release 9.0 (Research Triangle Institute, Research Triangle Park, NC, USA). SUDAAN was used to adjust for survey design effects resulting from NHANES' complex, multistage, probability sampling ${ }^{(6,17,18)}$.

Two-sided $t$ tests were used to detect differences between 2003-2004 and 2005-2006 estimates for the following variables: (i) percentage of individuals reporting any plain water; (ii) mean intake of total plain water; (iii) percentages reporting specific water types (tap, bottled); and (iv) mean intake of each water type. Dietary sample weights were applied in all analyses to produce nationally representative estimates.

\section{Results}

The percentages of individuals reporting total drinking water, tap water and plain bottled water on any given day in 2003-2004 and 2005-2006 are shown in Table 3. In $2005-2006,76 \cdot 9 \%$ of individuals aged $\geq 1$ year in the USA reported drinking some water. For the all-inclusive group of individuals aged $\geq 1$ year, all of the subgroups of males aged $\geq 14$ years and females aged $\geq 71$ years, percentages reporting total drinking water were significantly lower in 2005-2006 than in 2003-2004 $(P<0.001)$. In many of these age/gender groups, this decrease was driven by lower percentages reporting tap water in 2005-2006. The percentage of individuals reporting plain bottled water did not differ significantly between the two survey cycles.

The mean total drinking water intake of adults aged $\geq 19$ years in 2005-2006 was slightly more than 1 litre/ person per $\mathrm{d}$ (Table 4); this mean value is based on both reporters and non-reporters of water consumption. About $60 \%$ of that amount was tap water and about $40 \%$ was 
Table 2 Drinking water questions and variables in What We Eat in America/National Health and Nutrition Examination Survey 2003-2004 and 2005-2006

\begin{tabular}{|c|c|c|}
\hline \multirow[b]{2}{*}{ Year } & \multicolumn{2}{|c|}{ Type of water included and questions related to: } \\
\hline & Post-recall daily total water intake data & $24 \mathrm{~h}$ recall datat for each report of consuming water \\
\hline 2003-2004 & $\begin{array}{l}\text { Plain carbonated water - Did you drink any plain } \\
\text { carbonated water, seltzer water, club soda, and } \\
\text { carbonated bottled water such as Perrier? (If yes): } \\
\text { - What kind was it? (As appropriate): } \\
\text { - Was it sweetened (if so, it was recorded with } 24 \text { h recall } \\
\text { data) or unsweetened, diet or regular? } \\
\text { - How much of this water did you actually drink? } \\
\text { Tap water (includes filtered tap water and water from a } \\
\text { drinking fountain) - Did you drink any tap water } \\
\text { yesterday? (If yes): } \\
\text { - How much tap water did you drink yesterday? } \\
\text { Plain bottled water - Did you drink any plain water } \\
\text { yesterday that was bottled or from a water cooler (which } \\
\text { dispenses water from a large bottle)? (If yes): } \\
\text { - How much of this water did you actually drink? } \\
\text { Total plain water (calculated as sum of tap water and plain } \\
\text { bottled water) }\end{array}$ & $\begin{array}{l}\text { Sweetened water - What kind of water was it? Was } \\
\text { it tonic water, a sweetened flavoured water, or } \\
\text { something else? } \\
\text { (Response was matched to a } 60 \text {-item list of water } \\
\text { descriptions to determine which of the following } \\
\text { questions would be asked): } \\
\text { - Was it carbonated or uncarbonated? } \\
\text { - Was it diet, sweetened, or unsweetened? } \\
\text { - Was it diet or regular? } \\
\text { How much of this water did you actually drink? }\end{array}$ \\
\hline 2005-2006 & None & $\begin{array}{l}\text { All water - What kind of water was it? Was it tap } \\
\text { water, plain bottled water, tonic water, a } \\
\text { sweetened flavoured water, or something else? } \\
\text { (Response was matched to a 73-item list of water } \\
\text { descriptions to determine which of the following } \\
\text { questions would be asked): } \\
\text { - Was it carbonated or uncarbonated? } \\
\text { - Was it plain, diet, sweetened, or unsweetened? } \\
\text { - Was it diet or regular? } \\
\text { - How much of this water did you actually drink? }\end{array}$ \\
\hline
\end{tabular}

tIn all survey years, for types of water collected during the $24 \mathrm{~h}$ recall, the interviewer asked for enough information to assign the appropriate USDA food code. Since 2002, the USDA Automated Multiple-Pass Method guides the interviewer through a detailed path of standardized probes that are specific to water (only sweetened water in 2002-2004; all types of water starting in 2005). In general, $24 \mathrm{~h}$ recall data include a USDA food code identifying the type of water consumed, the amount consumed, the amounts of nutrients provided, the time and name of the eating occasion, and whether the water was consumed in combination with other foods.

bottled water. For total plain drinking water, no differences between 2003-2004 and 2005-2006 were found in mean intakes per person. Men aged $\geq 71$ years had a lower mean intake of tap water in 2005-2006 than in 2003-2004 (0.51 litre $v \cdot 0 \cdot 81$ litre; $P=0 \cdot 0002)$. There were no significant differences in estimates of plain bottled water intake per person for any of the age/gender groups.

\section{Discussion}

Twenty-four hour recalls are preferable to FFQ for obtaining valid, complete water intake reports ${ }^{(3)}$. USDA's AMPM (the $24 \mathrm{~h}$ recall method used in WWEIA) has been called the 'current state-of-the-art 24-hour dietary recall

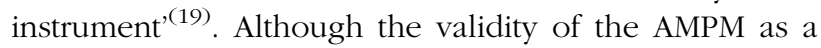
collection instrument for intakes of drinking water per se has not been tested, research has shown that the AMPM estimates energy intakes more accurately than FFQ do ${ }^{(20)}$. As shown by validation in doubly labelled water studies, the AMPM yields very accurate, unbiased energy estimates for highly motivated subjects ${ }^{(20)}$, although reporting bias is still possible among less motivated respondents and individuals classified as overweight or obese ${ }^{(5)}$.

The AMPM addresses the known issue of underreporting in intake surveys, having undergone extensive methodological testing to enhance food recall and thus minimize forgotten food items ${ }^{(5,21)}$. Starting in 2005-2006, specific mentions (probes) of water were incorporated into AMPM questions in order to encourage respondents to remember to report it. Water is included in both the introductory question ('Please tell me everything you had to eat and drink .. even snacks, coffee, soft drinks, water [italics added], and alcoholic beverages') and the final question ('Do you remember anything else you drank, including water (italics added) ...') of the $\mathrm{AMPM}^{(16)}$. Portion estimation aids including household cups, mugs and glasses and a detailed USDA Food Model Booklet are employed to help respondents estimate amounts consumed, a technique recommended to enhance water intake accuracy ${ }^{(3)}$. Additional features of the AMPM that encourage complete reporting are its administration by trained interviewers and the collection of the first day's intake (as used in the present analysis) in person ${ }^{(11,12)}$. 
Table 3 Percentages reporting total plain drinking water, tap water and plain bottled water, individuals aged $\geq 1$ year, What We Eat in America/National Health and Nutrition Examination Survey 2003-2004 and 2005-2006, 1 day†

\begin{tabular}{|c|c|c|c|c|c|c|c|c|c|c|c|c|}
\hline \multirow[b]{3}{*}{ Gender/age (years) } & \multicolumn{4}{|c|}{ Total plain drinking water } & \multicolumn{4}{|c|}{ Tap water } & \multicolumn{4}{|c|}{ Plain bottled water } \\
\hline & \multicolumn{2}{|c|}{ 2003-2004 } & \multicolumn{2}{|c|}{ 2005-2006 } & \multicolumn{2}{|c|}{ 2003-2004 } & \multicolumn{2}{|c|}{ 2005-2006 } & \multicolumn{2}{|c|}{ 2003-2004 } & \multicolumn{2}{|c|}{ 2005-2006 } \\
\hline & $\%$ & SE & $\%$ & SE & $\%$ & SE & $\%$ & $\mathrm{SE}$ & $\%$ & $\mathrm{SE}$ & $\%$ & SE \\
\hline \multicolumn{13}{|l|}{ Males and females } \\
\hline $1-3$ & $80 \cdot 4$ & $3 \cdot 2$ & $66 \cdot 4$ & $2 \cdot 5$ & $59 \cdot 2$ & $3 \cdot 8$ & $47 \cdot 6$ & $2 \cdot 8$ & $28 \cdot 5$ & $2 \cdot 8$ & $23 \cdot 9$ & $2 \cdot 6$ \\
\hline $4-8$ & $84 \cdot 6$ & $2 \cdot 3$ & $76 \cdot 2$ & $2 \cdot 6$ & $69 \cdot 2$ & $3 \cdot 2$ & $59 \cdot 9$ & $2 \cdot 8$ & $28 \cdot 9$ & $2 \cdot 9$ & $23 \cdot 9$ & $2 \cdot 7$ \\
\hline \multicolumn{13}{|l|}{ Males } \\
\hline $9-13$ & 88.9 & $2 \cdot 3$ & $77 \cdot 4$ & $2 \cdot 4$ & $72 \cdot 9$ & $3 \cdot 7$ & $65 \cdot 8$ & $2 \cdot 2$ & $28 \cdot 4$ & $4 \cdot 2$ & $25 \cdot 6$ & $2 \cdot 3$ \\
\hline $14-18$ & 88.5 & $1 \cdot 7$ & $72 \cdot 2^{\star \star \star}$ & $2 \cdot 8$ & $73 \cdot 9$ & $2 \cdot 9$ & $50 \cdot 5^{\star \star \star}$ & 3.9 & $38 \cdot 6$ & $3 \cdot 0$ & $26 \cdot 5$ & $3 \cdot 6$ \\
\hline $19-30$ & $87 \cdot 8$ & 1.9 & $74 \cdot 3^{\star \star \star}$ & $2 \cdot 8$ & $62 \cdot 0$ & $3 \cdot 3$ & $47 \cdot 9$ & $3 \cdot 4$ & $42 \cdot 4$ & $3 \cdot 1$ & $35 \cdot 1$ & $2 \cdot 3$ \\
\hline $31-50$ & $87 \cdot 3$ & $2 \cdot 0$ & $73 \cdot 5^{\star \star \star}$ & $1 \cdot 8$ & $64 \cdot 5$ & $3 \cdot 8$ & $49 \cdot 1^{\star \star \star}$ & $1 \cdot 7$ & $41 \cdot 2$ & $3 \cdot 0$ & $35 \cdot 8$ & $2 \cdot 4$ \\
\hline $51-70$ & $88 \cdot 4$ & $1 \cdot 9$ & $74 \cdot 1^{* \star *}$ & $2 \cdot 5$ & $70 \cdot 1$ & $3 \cdot 2$ & $54 \cdot 8$ & $3 \cdot 8$ & $29 \cdot 9$ & $3 \cdot 6$ & $26 \cdot 5$ & $3 \cdot 1$ \\
\hline$\geq 71$ & $91 \cdot 3$ & $1 \cdot 6$ & $73 \cdot 8^{\star \star \star}$ & $2 \cdot 3$ & $81 \cdot 6$ & $1 \cdot 4$ & $61 \cdot 6^{\star \star \star}$ & $3 \cdot 7$ & $17 \cdot 7$ & $3 \cdot 4$ & $15 \cdot 1$ & $2 \cdot 5$ \\
\hline All males $\geq 19$ & $88 \cdot 1$ & $1 \cdot 4$ & $73 \cdot 9^{\star \star \star}$ & 1.5 & $67 \cdot 1$ & $2 \cdot 5$ & $51 \cdot 6^{\star \star \star}$ & $1 \cdot 8$ & $36 \cdot 1$ & $2 \cdot 6$ & $31 \cdot 0$ & 1.5 \\
\hline \multicolumn{13}{|l|}{ Femalesł } \\
\hline $9-13$ & 88.5 & $3 \cdot 4$ & $80 \cdot 9$ & $2 \cdot 0$ & $70 \cdot 3$ & $4 \cdot 5$ & $56 \cdot 9$ & $4 \cdot 7$ & $32 \cdot 1$ & $3 \cdot 6$ & $28 \cdot 6$ & $3 \cdot 4$ \\
\hline $14-18$ & $85 \cdot 3$ & $3 \cdot 5$ & $74 \cdot 0$ & $2 \cdot 7$ & $64 \cdot 7$ & $4 \cdot 5$ & $45 \cdot 7$ & $2 \cdot 9$ & $40 \cdot 9$ & $4 \cdot 0$ & $38 \cdot 4$ & 3.5 \\
\hline $19-30$ & $81 \cdot 4$ & $3 \cdot 5$ & $76 \cdot 2$ & 3.9 & $57 \cdot 3$ & $4 \cdot 8$ & $45 \cdot 4$ & 3.9 & $45 \cdot 1$ & $3 \cdot 4$ & $38 \cdot 6$ & $2 \cdot 8$ \\
\hline $31-50$ & $85 \cdot 1$ & $2 \cdot 3$ & $81 \cdot 3$ & $2 \cdot 0$ & $61 \cdot 7$ & $3 \cdot 3$ & $52 \cdot 5$ & $3 \cdot 7$ & $40 \cdot 9$ & $3 \cdot 1$ & $41 \cdot 0$ & $2 \cdot 1$ \\
\hline $51-70$ & $90 \cdot 4$ & $2 \cdot 2$ & $85 \cdot 9$ & $1 \cdot 6$ & $70 \cdot 4$ & $2 \cdot 2$ & $61 \cdot 9$ & $3 \cdot 0$ & $33 \cdot 4$ & $3 \cdot 2$ & $31 \cdot 3$ & $2 \cdot 7$ \\
\hline$\geq 71$ & $94 \cdot 0$ & $1 \cdot 4$ & $80 \cdot 4^{\star \star \star}$ & $2 \cdot 0$ & $81 \cdot 2$ & $2 \cdot 9$ & $67 \cdot 8^{\star \star \star}$ & $1 \cdot 8$ & $16 \cdot 9$ & $2 \cdot 6$ & $15 \cdot 8$ & $3 \cdot 1$ \\
\hline All females $\geq 19$ & $87 \cdot 1$ & $2 \cdot 0$ & $81 \cdot 6$ & $1 \cdot 3$ & $65 \cdot 9$ & $2 \cdot 3$ & $56 \cdot 0$ & $2 \cdot 5$ & $36 \cdot 4$ & $2 \cdot 2$ & $34 \cdot 4$ & $1 \cdot 3$ \\
\hline All individuals $\geq 1 \ddagger$ & $87 \cdot 1$ & $1 \cdot 3$ & $76 \cdot 9^{\star \star \star}$ & $1 \cdot 1$ & $67 \cdot 0$ & $2 \cdot 1$ & $54 \cdot 1^{\star \star \star}$ & 1.9 & $35 \cdot 2$ & $2 \cdot 0$ & $31 \cdot 3$ & $1 \cdot 2$ \\
\hline
\end{tabular}

${ }^{\star * *}$ Percentage was significantly different from that reporting the same type of water in 2003-2004 $(P<0 \cdot 001)$.

tSample weighted to be representative of the US population.

‡Excludes pregnant and lactating females.

Table 4 Mean intakes of total plain drinking water, tap water and plain bottled water, individuals aged $\geq 1$ year, What We Eat in America/ National Health and Nutrition Examination Survey 2003-2004 and 2005-2006, 1 day†

\begin{tabular}{|c|c|c|c|c|c|c|c|c|c|c|c|c|}
\hline \multirow[b]{3}{*}{ Gender/age (years) } & \multicolumn{4}{|c|}{ Total plain drinking water } & \multicolumn{4}{|c|}{ Tap water } & \multicolumn{4}{|c|}{ Plain bottled water } \\
\hline & \multicolumn{2}{|c|}{ 2003-2004 } & \multicolumn{2}{|c|}{ 2005-2006 } & \multicolumn{2}{|c|}{ 2003-2004 } & \multicolumn{2}{|c|}{ 2005-2006 } & \multicolumn{2}{|c|}{ 2003-2004 } & \multicolumn{2}{|c|}{ 2005-2006 } \\
\hline & Mean (litres) & SE & Mean (litres) & SE & Mean (litres) & SE & Mean (litres) & SEM & Mean (litres) & SEM & Mean (litres) & SEM \\
\hline \multicolumn{13}{|l|}{ Males and females } \\
\hline $1-3$ & $0 \cdot 30$ & 0.02 & 0.26 & 0.02 & $0 \cdot 21$ & 0.02 & $0 \cdot 16$ & 0.02 & 0.09 & 0.01 & 0.09 & 0.01 \\
\hline $4-8$ & 0.44 & 0.04 & $0 \cdot 40$ & 0.03 & $0 \cdot 30$ & 0.03 & 0.29 & 0.03 & $0 \cdot 14$ & $0 \cdot 02$ & $0 \cdot 11$ & 0.01 \\
\hline \multicolumn{13}{|l|}{ Males } \\
\hline $9-13$ & 0.59 & 0.06 & 0.58 & 0.06 & 0.44 & 0.06 & $0 \cdot 40$ & 0.05 & $0 \cdot 16$ & 0.02 & $0 \cdot 17$ & 0.02 \\
\hline $14-18$ & $1 \cdot 06$ & 0.07 & 0.90 & $0 \cdot 10$ & 0.73 & 0.06 & $0 \cdot 61$ & 0.09 & 0.33 & 0.03 & $0 \cdot 30$ & 0.06 \\
\hline $19-30$ & $1 \cdot 37$ & 0.09 & $1 \cdot 11$ & 0.07 & $0 \cdot 86$ & 0.08 & $0 \cdot 64$ & 0.06 & 0.51 & 0.05 & $0 \cdot 47$ & 0.04 \\
\hline $31-50$ & $1 \cdot 23$ & 0.07 & $1 \cdot 20$ & 0.07 & $0 \cdot 79$ & 0.06 & 0.69 & 0.05 & 0.43 & 0.06 & $0 \cdot 50$ & 0.05 \\
\hline $51-70$ & $1 \cdot 05$ & 0.04 & $0 \cdot 90$ & 0.05 & $0 \cdot 77$ & 0.05 & 0.58 & 0.05 & $0 \cdot 28$ & 0.04 & $0 \cdot 31$ & 0.05 \\
\hline$\geq 71$ & 0.91 & 0.04 & $0 \cdot 66$ & 0.06 & $0 \cdot 81$ & 0.04 & $0.51^{\star \star \star}$ & 0.06 & $0 \cdot 10$ & 0.02 & $0 \cdot 15$ & 0.03 \\
\hline All males $\geq 19$ & $1 \cdot 18$ & 0.05 & $1 \cdot 04$ & 0.05 & $0 \cdot 80$ & 0.04 & 0.63 & 0.04 & 0.38 & 0.03 & 0.41 & 0.03 \\
\hline \multicolumn{13}{|l|}{ Femalesł } \\
\hline $9-13$ & 0.53 & 0.03 & $0 \cdot 61$ & 0.04 & $0 \cdot 36$ & 0.03 & $0 \cdot 41$ & 0.03 & $0 \cdot 17$ & 0.03 & $0 \cdot 21$ & 0.06 \\
\hline $14-18$ & $0 \cdot 87$ & 0.08 & $0 \cdot 71$ & 0.06 & 0.57 & 0.09 & $0 \cdot 36$ & 0.05 & $0 \cdot 30$ & 0.03 & $0 \cdot 35$ & 0.04 \\
\hline $19-30$ & $1 \cdot 13$ & $0 \cdot 11$ & $1 \cdot 11$ & $0 \cdot 11$ & $0 \cdot 68$ & 0.09 & $0 \cdot 61$ & $0 \cdot 10$ & 0.45 & 0.05 & 0.50 & 0.05 \\
\hline $31-50$ & $1 \cdot 17$ & 0.08 & $1 \cdot 13$ & 0.09 & $0 \cdot 77$ & 0.08 & $0 \cdot 62$ & 0.08 & 0.40 & 0.04 & 0.52 & 0.05 \\
\hline $51-70$ & $1 \cdot 13$ & 0.07 & $1 \cdot 07$ & 0.06 & $0 \cdot 83$ & 0.05 & $0 \cdot 71$ & 0.06 & $0 \cdot 30$ & 0.04 & $0 \cdot 36$ & 0.03 \\
\hline$\geq 71$ & $0 \cdot 88$ & 0.05 & $0 \cdot 72$ & 0.05 & $0 \cdot 76$ & $0 \cdot 04$ & $0 \cdot 60$ & 0.04 & $0 \cdot 12$ & 0.03 & $0 \cdot 13$ & 0.04 \\
\hline All females $\geq 19$ & $1 \cdot 11$ & 0.06 & $1 \cdot 06$ & 0.06 & $0 \cdot 77$ & 0.04 & $0 \cdot 64$ & 0.06 & $0 \cdot 34$ & 0.03 & $0 \cdot 42$ & 0.03 \\
\hline All individuals $\geq 1 \ddagger$ & $1 \cdot 00$ & 0.04 & 0.92 & 0.04 & 0.69 & 0.03 & 0.56 & 0.04 & $0 \cdot 32$ & 0.02 & 0.36 & 0.02 \\
\hline
\end{tabular}

***Mean value was significantly different from that for the same type of water in 2003-2004 $(P<0.001)$.

tSample weighted to be representative of the US population. Includes both reporters and non-reporters of water.

$\ddagger$ Excludes pregnant and lactating females.

For all of these reasons, it is reasonable to consider the current method of collecting drinking water intake data preferable to earlier methods.

The mean intake of bottled water by all individuals aged $\geq 2$ years did not differ significantly between 2003-2004
(0.32 litre) and 2005-2006 (0.36 litre). However, the magnitude of the non-significant difference between those intakes $(+0.04$ litre/d) aligns well with that of the apparent increasing trend in bottled water consumption in the USA based on disappearance data ${ }^{(22)}$. 
Decreases were found in the percentages of individuals reporting tap water in several age/gender groups and in the mean intake of tap water by males aged $\geq 71$ years. Although it is possible that a real change in tap water intake occurred between 2003-2004 and 2005-2006, the cross-sectional, observational nature of the present study makes it impossible to distinguish secular trends from artefacts related to methodological changes. Increased sales of unsweetened carbonated (sparkling), flavoured and enhanced waters during this time period ${ }^{(23)}$ are unlikely to explain the lower percentages reporting tap water in 2005-2006, since the number of WWEIA respondents who reported these kinds of water was very low in both 2003-2005 and 2005-2006. Environmental factors could explain some of the observed differences in reporting between the survey periods. For example, a drought in the Southeast USA during 2005 through the winter of $2007^{(24)}$ may have caused changes in drinking water consumption behaviour in that region during the 2005-2006 data collection. As to whether the method change might explain the differences in intake estimates, the AMPM's demonstrated performance in collecting complete food intake data ${ }^{(5)}$ makes it highly unlikely that collecting water data via the AMPM would result in increased under-reporting. Rather, the opposite is more likely: namely, that less over-reporting of tap water intakes occurred in 2005-2006 when all water data were collected via AMPM than in the earlier survey period when they were collected via FFQ-type questions.

One conclusion that can be drawn from the differences in percentages of individuals reporting water and in mean water intakes between 2003-2004 and 2005-2006 is that it may be inappropriate to combine data from older survey cycles with newer data, at least for some age/gender groups. Trends analysis of water intake data may be contraindicated as well, given the (possible) impact of this methodological change. The findings of the present study illustrate the importance of careful examination of survey variables before either conducting trends analysis or combining data from multiple WWEIA/NHANES survey cycles. Despite these caveats, these data provide benchmark estimates of drinking water intake in the USA; invaluable information that is appropriate to use to address a myriad of research questions.

Researchers should note the analytic benefits afforded by the new method of collecting water data using the AMPM. Among these benefits, the most evident is that the WWEIA/NHANES total nutrient intake data files now include drinking water's contribution not only to moisture, but also to the nutrients $\mathrm{Ca}, \mathrm{Cu}, \mathrm{Mg}, \mathrm{Na}$ and $\mathrm{Zn}$. Additionally, this methodological change has greatly extended the array of variables that are available for analyses involving water beyond its nutrient contributions. Data for each report of tap or plain bottled water now include a USDA food code identifying the type of water consumed, the amount (in grams) consumed on that occasion, the intake day of the week, the main language in which the interview was conducted, the time each eating occasion began, the name by which the respondent referred to the eating occasion (breakfast, snack, etc.), whether the water was consumed at home or not, and (for bottled water only) where it was obtained ${ }^{(11)}$. This additional information provides new possibilities for examining water consumption patterns.

\section{Acknowledgements}

This contribution is the work of US Government employees and is not subject to copyright protection in the USA. The funding source for this study was the USDA. The contents of this publication do not necessarily reflect the views or policies of USDA, nor does mention of trade names, commercial products or organizations imply endorsement from the US Government. None of the authors had a conflict of interest. R.S.S. contributed to the concept, design, analysis, interpretation of results and writing of the manuscript; C.W.E. contributed to the concept, literature review, interpretation of results, creation of tables and writing of the manuscript; J.D.G. contributed to the design and analysis and conducted the programming; A.J.M. contributed to the concept and design of the study. All co-authors reviewed and critiqued multiple drafts of the manuscripts.

\section{References}

1. Institute of Medicine (2005) Dietary Reference Intakes for Water, Potassium, Sodium, Chloride, and Sulfate. Washington, DC: National Academies Press.

2. Ershow AG \& Cantor KP (1989) Total Water and Tapwater Intake in the United States: Population-Based Estimates of Quantities and Sources. Bethesda, MD: Federation of American Societies for Experimental Biology, Life Sciences Research Office.

3. Mons MN, van der Wielen JML, Blokker EJM et al. (2007) Estimation of the consumption of cold tap water for microbiological risk assessment: an overview of studies and statistical analysis of data. $J$ Water Health 5, Suppl. 1, S151-S170

4. Stookey JD, Constant F, Gardner CD et al. (2007) Replacing sweetened caloric beverages with drinking water is associated with lower energy intake. Obesity (Silver Spring) 15, 3013-3022.

5. Moshfegh AJ, Rhodes DG, Baer DJ et al. (2008) The US Department of Agriculture Automated Multiple-Pass Method reduces bias in the collection of energy intakes. Am J Clin Nutr 88, 324-332.

6. US Department of Health and Human Services, Centers for Disease Control and Prevention, National Center for Health Statistics (2006) Analytic and reporting guidelines. http:// www.cdc.gov/nchs/data/nhanes/nhanes_03_04/nhanes_ analytic_guidelines_dec_2005.pdf (accessed May 2011).

7. Kant AK, Graubard BI \& Atchison EA (2009) Intakes of plain water, moisture in foods and beverages, and total water in the adult US population - nutritional, meal pattern, and body weight correlates: National Health and Nutrition Examination Surveys 1999-2006. Am J Clin Nutr 90, 655-663. 
8. Kant AK \& Graubard BI (2010) Contributors of water intake in US children and adolescents: associations with dietary and meal characteristics - National Health and Nutrition Examination Survey 2005-2006. Am J Clin Nutr 92, 887-896.

9. Popkin BM, D'Anci KE \& Rosenberg IH (2010) Water, hydration, and health. Nutr Rev 68, 439-458.

10. Popkin BM (2010) Patterns of beverage use across the lifecycle. Physiol Behav 100, 4-9.

11. US Department of Agriculture, Agricultural Research Service, Beltsville Human Nutrition Research Center, Food Surveys Research Group \& US Department of Health and Human Services, Centers for Disease Control and Prevention, National Center for Health Statistics (2008) What We Eat in America, NHANES 2005-2006 documentation: Dietary interview - individual foods - first day (DR1IFF_D). http://www.cdc.gov/nchs/data/nhanes/nhanes_05_06/dr1iff_ d.pdf (accessed May 2011).

12. US Department of Agriculture, Agricultural Research Service, Beltsville Human Nutrition Research Center, Food Surveys Research Group \& US Department of Health and Human Services, Centers for Disease Control and Prevention, National Center for Health Statistics (2007) What We Eat in America, NHANES 2003-2004 documentation: Dietary interview - individual foods - first day (DR1IFF_C). http://www.cdc.gov/nchs/data/nhanes/nhanes_03_04/dr1iff_ c.pdf (accessed May 2011).

13. US Department of Health and Human Services, Centers for Disease Control and Prevention, National Center for Health Statistics (2005) NHANES 2005-2006 public data general release file documentation. http://www.cdc.gov/nchs/data/ nhanes/nhanes_05_06/general_data_release_doc_05_06.pdf (accessed May 2011).

14. US Department of Health and Human Services, Centers for Disease Control and Prevention, National Center for Health Statistics (2005) NHANES 2003-2004 public data general release file documentation. http://www.cdc.gov/nchs/ data/nhanes/nhanes_03_04/general_data_release_doc_0304.pdf (accessed May 2011).

15. US Department of Health and Human Services, Centers for Disease Control and Prevention, National Center for
Health Statistics (2002) MEC In-Person Dietary Interviewers Procedures Manual. http://www.cdc.gov/nchs/data/ nhanes/nhanes_03_04/DIETARY_MEC.pdf (accessed May 2011).

16. US Department of Health and Human Services, Centers for Disease Control and Prevention, National Center for Health Statistics (2006) NHANES 2005-2006 MEC in-person dietary interviewers procedures manual. http://www.cdc.gov/ nchs/data/nhanes/nhanes_05_06/DIETARY_MEC.pdf (accessed May 2011).

17. Research Triangle Institute (2004) SUDAAN Language Manual, Release 9.0. Research Triangle Park, NC: Research Triangle Institute.

18. US Department of Health and Human Services, Centers for Disease Control and Prevention, National Center for Health Statistics (2009) Sample Design. In Continuous NHANES web tutorial. http://www.cdc.gov/nchs/tutorials/Nhanes/ SurveyDesign/SampleDesign/intro.htm (accessed April 2011).

19. Thompson FE \& Subar AF (2008) Dietary assessment methodology. In Nutrition in the Prevention and Treatment of Disease, 2nd ed., pp. 3-30 [AM Coulston and CJ Boushey, editors]. Boston, MA: Elsevier Academic Press.

20. Blanton CA, Moshfegh AJ, Baer DJ et al. (2006) The USDA Automated Multiple-Pass Method accurately estimates group total energy and nutrient intake. J Nutr 136, 2594-2599.

21. Raper N, Perloff B, Ingwersen L et al. (2004) An overview of USDA's dietary intake data system. J Food Compost Anal 17, 545-555.

22. Earth Policy Institute (2007) Bottled water consumption per person in the United States, 1976-2007. http://www. earth-policy.org/index.php?/data_center/C21/ (accessed May 2011).

23. ECONorthwest (2007) The potential economic effects of the proposed water bottling facility in McCloud. http:// www.econw.com/reports/ECONorthwest_McCloud\%20 Economic\%20Analysis.pdf (accessed January 2012).

24. Manuel J (2008) Drought in the Southeast: lessons for water management. Environ Health Perspect 116, A168-A171. 